\title{
Reply to Hawthorne
}

\author{
ALLAN GIBBARD
}

University of Michigan, Ann Arbor

Goodness, rational permissibility, and the like might be gruesome properties. That is to say, they might not well suit causal-explanatory purposes. Or at least, these properties are gruesome for all their normative concepts tell us by themselves. Perhaps hedonists are right and such properties are anything but gruesome, but perhaps instead, the most gruesome-minded ethical pluralists are right-normative concepts by themselves don't settle the issue. At the end of his marvelous commentary, John Hawthorne depicts the morass of dank possibilities that a "moral realist" must enter when he tries explaining how normative words and thoughts could lock on to some particular causally gruesome property that constitutes being good. Right, I say, and expressivists can direct us around the morass. Then he asks why I avoid the questions that lead moral realists into this morass. But I don't avoid them; I offer an answer.

How do plan-laden terms and concepts pick out properties? ${ }^{1}$ Not all by themselves, in a way that a theory of interpretation can explain on its own. Interpretation might identify a term as plan-laden, as meaning, say, "is the thing to do" in the special sense I stipulated for that phrase. Trivially, if that's what the term means, then it picks out whatever property constitutes being the thing to do-but what property is that? What property it is, I say, is a question of what to do. It's a question of what to do in general, of how to live. Come to a full plan for life, and you will have come to a view on what property constitutes being the thing to do. Will you have the answer right? Again, that's not settled just by interpreting your words and concepts; that again is a question of how to live. It can be answered only in plan-laden terms. Does a term that means "thing to do" pick out the property of holding out maximal prospects for pleasure, as a normative hedonist would claim? That's a question of whether to go for pleasure and pleasure alone.

That is the account I offer. By stipulation, it applies to "plan-laden" terms like "thing to do"-if my stipulations are coherent. Does it apply as well to normative terms like 'ought' and 'good' in our actual language? I respond in

I mean, of course, one-place predicates and their concepts. Like questions arise for multi-place plan-laden predicates. 
two stages: First, a "possibility proof": I try to show that the planning language of "thing to do" is coherent. Second, support for the hypothesis that our normative language is plan-laden.

Suppose first, then, that plan-laden language is a coherent possibility. Still, asks Hawthorne, why not stick with more standard accounts for the workings of language and just apply them to normative terms? Well, as he points out, orthodox accounts lead us into the morass. They leave us with the problem of causally gruesome properties: how one of these could possibly be what a normative term picks out. And in this morass lie other pitfalls: Standard accounts leave it a mystery why to do what you ought to do-whereas why to do it seems to be settled in settling that you ought to. Standard accounts don't explain why, say, perfectionists and hedonists might both have the concept ought, and with full command of the natural facts, still disagree-and each understand what the other was saying. An account that led us around this morass would have advantages.

That leaves the possibility proof and Hawthorne's objections to it. First, though, let me address some of Hawthorne's worries about how I'm saying that plan-laden concepts work. He is right that I need to change what I say about natural properties and supervenience. I'll stick to my claim, though, that a luminosity requirement belongs in the kind of idealization that will illuminate the nature and logic of planning and of normative concepts.

What to do, then, if you see a ghost? Have your head examined, I would think. What, though, if the ghost is real? That's not a serious question until we learn how you're supposed to tell that it's real-and if someone offers us an answer, our first question should be whether, confronted with that apparition, to conclude that it's a real ghost you are seeing. What if instead you encounter a halo of goodness? We'd need to learn more about halos. If touching a halo of goodness makes you go poof and turn into a halo too, the thing to do, l'd think, is to get away.

Strange enough evidence might support strange conclusions: that there were more things on earth than are admitted by naturalistic philosophy. So yes, a universal plan may provide for what to do if the thing to conclude is that you are seeing a ghost. In this sense, it might provide for encountering ghosts—or even "halos of goodness", when we learn what those are. Features of plans, then, I agree, can be couched in "objective" terms, in terms of what to do given a situation, like really encountering a ghost, apart from any question of how you'd know you were in that situation. Such plan fragments can be useful in our thinking; "Don't cross the street when a car is coming" can be useful advice; even "Buy low and sell high" can be useful. And nothing in the logic of planning, I agree, precludes ghosts and halos in the objective situations for which we plan. The question of what you ought to do if you meet a ghost may be intelligible even if idle. On this, Hawthorne is quite right, and I need to speak more carefully than I have been doing. 
Two claims I now want to make. First, planning how to cope with evidence is, in a sense, more basic that planning for objective situations you might be in. Second, when ghostly or haloly properties figure in planning, these aren't "non-natural" in the sense that Moore found he needed. Moore argued that his objections to naturalistic ethics applied to theological ethics too; supernatural properties weren't non-natural in the sense that concerned him. My central claims, put more cautiously than I did, should be these: (i) the plan-laden supervenes on that which is not plan-laden, and (ii) it is concepts, not properties, that are plan-laden or not. (I do think the only objective situations we'll ever encounter are natural ones, but that's a matter of how the world is constructed, not of how plan-laden concepts work.) My hypothesis is that like claims hold for what's normative or not: for ought and the like. "Naturalistic", then, isn't the right contrast with "normative ", I'll agree. Perhaps "descriptive" is the best term for the non-normative side of the contrast, as Hare proposes-but that term is bound to be treacherous, with suggestions that I won't want to embrace. What I am hypothesizing is that normative concepts need quite a different kind of explanation from naturalistic concepts, from supernaturalistic concepts, and from any other concepts that might be best explained in one of the ways that Hawthorne toys with.

As for the concept of a "halo of goodness", if it's normative, then it won't suit fundamental contingency planning. If the concept of a "halo" has built into it that halos are to be sought, then "Seek halos" is empty; to settle whether something counts as a halo, we must first settle whether to seek it. Counting something as a halo is then a deliverance of contingency planning, not an input. Alternatively, halos are recognizable apart from questions of what to do with them, and so the concept of a halo is non-normative: it is conceptually coherent to shun halos. In other words, I say the same thing about "halos of goodness" as I said about situational demands to bash a man. If, as a deliverance of metaphysics, genocide is surrounded by a halo of goodness, still genocide is not a goal to pursue. I say this as a planner, and trust that you agree.

Do normative claims express facts? In some ways yes and in some ways no. If Holmes ought now to pack, there's a non-normative fact that constitutes this being so. I might be mistaken, though, about what that fact is, and yet not be making any conceptual or other non-normative mistake. The fact is a hedonic fact $H$, perhaps, and I'm a perfectionist who, moreover, thinks that $H$ doesn't obtain. I'm mistaken on how to live, and mistaken about $H$. Do I "express" this non-normative fact $H$ that I deny? In a sense I do, perhaps, but in a sense I don't.

Back then to planning for objective circumstances. What to do if you're about to cross the street and a car's speeding toward you? Wait, is the answer. The question is couched in terms of one's objective situation, and the answer seems obvious. Isn't that, however, because it goes without saying how to 
recognize such a plight? The full story, idealized to an extreme, consists in how to respond to evidence. "If a car's coming, wait!" can amount to this: if the thing to think, given your evidence, is that a car is coming, then wait! Can we understand plans for objective contingencies, except as fragments of evidentially based plans? "Save money" is often a good dictum. So, it seems, if your house isn't going to burn down, don't waste money on insurance. This plan is as implementable as any: that your house won't burn down next week is a virtual certainty. But this is ridiculous, and so "Save money" can't reasonably mean, "When it's virtually certain that an act will save money, do it." We'll know what it does mean when we cash it out in terms of how to respond to evidence, including evidence of risks that are minimal.

Speaking as I am speaking does, of course, involve a huge idealization. An ideally full, coherent plan, I'm saying, would be in terms of evidence and how to respond. Human wisdom isn't like this, I agree; we can't implement fully coherent plans, any more that we take a fully coherent survey of how things may stand for all we know. No evidence is fully luminous to us, perhaps. For purposes of logic, though, it is useful to look to coherent idealizations, even if for navigating life, we make do with rough heuristics. The logic of how things stand goes beyond our powers to keep track of the possibilities, and the like goes for plans.

Two odds and ends: third person uses and akrasia. If I say, "The thing for Holmes to do now is to pack," 1 express a contingency plan for being in his shoes. To accept this is to plan, for the contingency of being in Holmes's exact subjective circumstances, to pack. (The story gets more complex when I'm uncertain what his subjective circumstances are, but here I'll leave this thread dangling.) The akratic agent isn't of one mind: in a way he accepts a plan, and in a way he doesn't fully accept it. If I think I ought to leave now but I don't, I don't entirely accept that I ought to leave right this instant.

I turn now to the most serious problem for the possibility proof, rejection or disagreement. First, instead of appealing to these notions, why not do logic by appealing to standard introduction and elimination rules? Well, I'd be happy if that works. It would make things easier-so long as we didn't let it lead us back into the morass. Dreier's "hiyo" example, though, makes me think that this alternative won't work; his moral is that we can't always just invent a predicate and stipulate it to have a standard logic. The example led me to think that Stevenson had been right, and the possibility of disagreement is the key to logic. Not all kinds of rejection of a state of mind, though, constitute disagreeing in a sense that could underlie logic. I used the word "reject" in my derivation of a logic of planning, but as Hawthorne rightly points out, not every kind of rejection of a state of mind will fit my needs. ${ }^{2}$ 
Can you disagree with a plan? "Ruling out" adopting it, I now agree, might not read as disagreeing with it; I might rule out adopting any plan whatsoever. Belief runs parallel: an agnostic of one kind rules out adopting any belief whatsoever as to whether God exists, ruling out agreeing and ruling out disagreeing that He exists. I need ruling out in the sense of disagreeing, where disagreeing with disagreeing amounts to agreeing.

Can I agree or disagree with doing something? Mrs. Hudson calls the police, and Holmes, we might say, disagrees with what she does. If I disagree with Holmes on this, I regard calling the police, in her circumstances, as okay to do-as rationally permissible. If I disagree with not calling the police, I regard calling them as mandatory. Disagreement can explain the distinction between permissions and requirements.

Whether there's an attitude of disagreement that will do these jobs is a big question, and I won't try to settle it here. Hawthorne (and Unwin) are right to identify this as the crux of whether expressivism will work. I hope it does, because I'd like to avoid the morass and see the Moore-like phenomena fall neatly out of a theory.

I thank John Hawthorne for a clear and insightful commentary, one that has led me to rethink aspects of my position. 